Changing life worlds and contested space : Seclusion practices among the Iraqw of Northern Tanzania

Jonathan Baker et Hege Wallevik

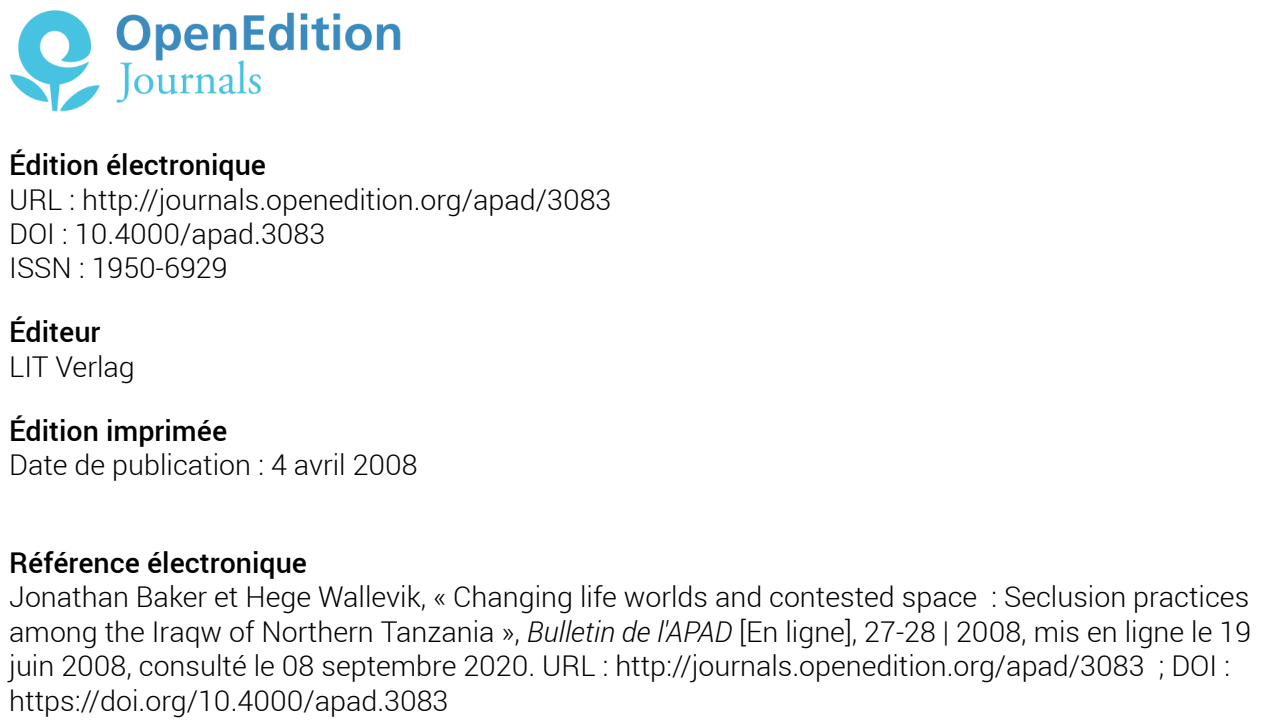

Ce document a été généré automatiquement le 8 septembre 2020

Bulletin de l'APAD 


\title{
Changing life worlds and contested space : Seclusion practices among the Iraqw of Northern Tanzania
}

\author{
Jonathan Baker et Hege Wallevik
}

Introduction

This paper focuses on the seclusion practices (meeta) of the Cushitic-speaking Iraqw people of northern Tanzania who are mainly concentrated in Mbulu District. The headquarters of Mbulu District is the town of Mbulu. Despite its size, Mbulu town can be considered as a 'node of economic and social opportunity' (Baker 2001 : 122) and is an important place providing a wide range of goods and services for its own population, as well as a large hinterland. At present, Mbulu town is undergoing what might be termed as a process of modernization. The town has a diversified population representing a mixture of lifestyles that influence the traditional Iraqw life world. Mbulu also has a large, mainly Catholic, Christian population. In spite of the apparent acceptance of modern urban life and Christianity on the part of many rural and urban Iraqw and below this veneer of imported dogma, traditional beliefs are strongly adhered to and influential Iraqw social and economic behaviour. Among many Iraqw there is a strong belief in the seclusion practices known as meeta. People who enter a state of meeta are considered dangerous and they are avoided by exclusion from their communities. The meeta sanction is particularly strong in rural communities and mainly affects women. The most common and most stringent forms of meeta involve cases where a girl becomes pregnant outside marriage, or where a woman suffers a miscarriage, stillbirth or the death of a child before it is weaned.

2 The argument presented here is that whether these seclusion practices of meeta are interpreted as social violence depends on the perspective. Consequently, if a Western perspective is applied, meeta practices can be interpreted as a system of social violence and the town of Mbulu can be seen as a liberating place for these women. On the other hand, meeta can be understood in terms of protection rather than punishment and the town then represents a dangerous space, which the traditional Iraqw people have to 
negotiate. This paper reveals how the Iraqw live with these contested meanings of a cultural praxis. According to Rekdal (1996: 382), there are about 150 Iraqw clans so generalizations about Iraqw culture are very often not valid at the local clan level. This was clearly found to be the case during periods of fieldwork. This paper is based on data collected in 2000-2005 in Mbulu town and the three surrounding villages of Gunyoda, Moringa and Murray (Map 1). ${ }^{1}$

The setting and context ${ }^{2} \mathrm{Mbulu}$ district

3 The town of Mbulu is the district headquarters for Mbulu District, (Map 1) which is one of the five districts of the newly created Manyara Region. Mbulu District has a total area of $4350 \mathrm{~km}^{2}$ and a population of 237,882 (URT $2003: 171$ ). The district population is overwhelmingly rural and is distributed over a total of 71 villages. Apart from Mbulu, the only other population centres of significance in the district are Haydom and Dongobesh, which perform a number of important functions for rural populations. The major ethnic group in the district is the Iraqw. While the Tanzanian census does not collect data on ethnic affiliation, the Iraqw can be considered one of the larger groups in the country. According to Mous (1992: 1), the Iraqw number around 500,000. In addition to the Iraqw, the district also has Nilotic Datooga pastoralists, who are estimated to number between 15,000 and 20,000 (Meindertsma \& Kessler $1997: 28$ ). Most Iraqw village households are involved in crop production and some livestock keeping, but the number and type of the latter depends upon the household's wealth. Population growth in the whole district is approximately $3.8 \%$ per annum, which is above the national average of $2.9 \%$ (URT $2003: 2$ ). This has led to land scarcity and, invariably, to a good deal of commercialization of rural land transactions. The problem of land scarcity appears to be intractable. The tradition among the Iraqw whereby the youngest son inherits the family land means that many other males are obliged to permanently migrate to urban centres in the district and elsewhere, or to migrate much further afield to acquire agricultural land. The irregularity of rainfall is also a problem and in some areas of the district there is rainfall and crop failure every two or three years out of ten.

The town of Mbulu

4 The population of Mbulu town is growing rapidly and, according to the latest population census conducted in 2002 had a population of 12,171 people in 2,514 households, which gives an average household size of 4.8 persons (URT 2003: 175). Within the urban boundary is a fairly compact core, which represents the commercial centre. As might be expected, the urban population is characterized by greater ethnic and religious heterogeneity than the rural population as a result of in-migration. This population mobility is driven by two factors: the transference of local and central government employees from other regions of the country as part of job relocation (a common policy in Tanzania), and the attraction of Mbulu for non-Iraqw outsiders because of the perceived business opportunities in the town. Given this mobility, it is not surprising that the town's non-Iraqw population is as high as 22 per cent of the total population. Concomitantly, the number of Iraqw traditional believers is only 12 per cent, while Christians comprise 82 per cent and Muslims 6 per cent. Despite its relatively small size, the town of Mbulu performs a range of important functions. It is :

- an administrative and control centre : with the district council administration, district police headquarters and district prison. 
- an educational centre : with four primary schools with a total of 1793 pupils. In addition, the town has three nationally recognized secondary schools, which partly cater for the needs of the large village population which only has access to primary schools.

- a health centre : the Mbulu District Hospital is the medical centre for the district and is run by the Ministry of Health.

- a communication centre : the post office provides postal services for the district, and also post bank and telephone services.

- the district's most important economic centre : The economic and employment structure of Mbulu has been influenced, to a large extent, by the fact that it is a central location catering to the needs of its own population, as well as the needs of a much larger rural population. The town is overwhelmingly a service centre and provides retailing, accommodation and bar and food services, in addition to small-scale repair facilities. Mbulu town's connection to the national electricity grid in 1999 has resulted in the electrification of grain mills, the introduction of welding activities and the installation of domestic and street lighting.

5 There are a number of very wealthy local businessmen who own capital-intensive enterprises such as petrol stations, grain mills, large lodging houses and much of the wholesale trade. However, the urban economic structure is dominated by numerous small-scale enterprises often of an informal nature. These include small general stores (sometimes referred to as kiosks if they are very small), itinerant traders and a range of individuals engaged in repairs. Mbulu has a daily and weekly market where rural produce can be purchased. A large market is held monthly on the outskirts of the town and attracts traders from as far away as Arusha. At the height of market day there are often more than 6,000 people at the market. It provides rural people with the chance to buy and sell large and small livestock. A whole range of manufactured goods are on sale and there are many stalls and tents selling cooked meat and local brews.

Three surveyed villages around Mbulu

Three villages were surveyed in an attempt to understand the socio-economic nature of rural life and to investigate the degree of village interaction with the town. These are dispersed village settlements extending over a large area : Murray $\left(28.4 \mathrm{~km}^{2}\right)$, Gunyoda $\left(60.8 \mathrm{~km}^{2}\right)$ and Moringa $\left(16.25 \mathrm{~km}^{2}\right)$. They ranged in population from 3,600 to 5,400. Each village has its own health clinic and at least one primary school. Gunyoda is located $12 \mathrm{~km}$ from Mbulu ( $3 \mathrm{~km}$ on the main road and $9 \mathrm{~km}$ along a narrow track). Moringa is $16 \mathrm{~km}$ from Mbulu, while Murray is the most isolated of the three villages. Although it is only $22 \mathrm{~km}$ from Mbulu it could take several hours to reach the town on foot because of the very hilly terrain. The ethnic composition of these villages is overwhelmingly Iraqw and in each village the proportion of Iraqw households was identical : 28 out of 30 households, or 93 per cent of all the households in each village. Non-Iraqw villagers are invariably incomers and usually represented transferred government workers such as teachers, community development officials, foresters, health workers and others. By religious adherence, the villages demonstrated a sharp division between Christians (invariably Catholics) and believers in local Iraqw divinities.

7 Despite the difficulties of accessibility to Mbulu (particularly for the residents of Murray village), rural people nevertheless made heavy use of the goods, services and other benefits to be found there, including a range of income-generating possibilities from selling labour to agricultural produce (grain, vegetables, livestock and timber) at the daily and weekly markets, as well as the very large monthly markets. Rural people 
clearly perceive the town of Mbulu as a place of social and economic opportunity. However, as is demonstrated below, the town is also considered a dangerous space, especially by rural women who still adhere to the rules and regulations of the traditional Iraqw way of life.

Central aspects of the Iraqw life worldThe supreme powers of Looaa and Neetlangw

As a backdrop to the discussion of meeta, it is essential to have an understanding of the supreme powers worshipped by the traditional Iraqw. Among these Iraqw, there are two different sets of divinities. Looaa is a female divinity associated with the sun and represents immense goodness and the fertile powers of rain and birth. She is venerated and thanked for providing protection against evil spirits and the avoidance of conflict, and people seek the blessing of Looaa to maintain the fertility of people, animals and the land. By contrast, Neetlangw is a powerful male divinity that can cause misfortune such as disease and drought. Appeasement of Neetlangw takes the form of animal sacrifice, often a sheep. Neetlangw is closely associated with water and inhabits water groves. Women who are in a state of meeta (seclusion) are considered by the traditional Iraqw to be possessed by Neetlangw and, as such, are extremely dangerous. Consequently, a woman in meeta can never collect water since she has the power to inflict great suffering or even destroy her own community, as well as the livestock. It is little wonder then that women possessed of such powers are not readily accepted back into their home communities after a period of meeta unless they undergo a process to rid themse; ves of spirit possession. This process can be likened to an exorcism practised by some Christian churches. Briefly, the cleansing ritual involves a process whereby the spirit-possessed woman is subjected to physical and verbal vilification to exorcize the evil spirit. Specifically, excrement from a recently sacrificed sheep is thrown at the woman while incantations are screamed at the spirit to leave the body of the possessed person. The final stage in becoming ritually clean is to have body hair removed. During this cleansing process, family and same-clan members are not involved but a medicine man from another clan takes responsibility.

The seclusion practices of Meeta

9 Meeta practices are frequently mentioned in ethnographic accounts of the Iraqw people (Winter 1968, Thornton 1980, Rekdal 1991, Snyder 1993, Rekdal \& Blystad 1999). The term meeta is not easily translated and is consequently open to different interpretations. Thornton (1980) understands meeta as a form of ritual impurity, while Snyder (1993: 17) argues that meeta should be translated as 'a quarantine created to contain pollution'. Selvik's approach appears to have greatest merit since it allows for a wider interpretation of a complex condition rather than the simple and blanket approach adopted by other writers. According to Selvik (1998:3), meeta refers to 'a complex of rules and practices which Iraqw people observe in everyday life, but which become most intensive after particular incidents'. At the outset, it must be stressed that broad generalizations concerning meeta can often be misleading. For example, the practice of meeta is particularly strong among certain Iraqw clans. The clans of Gunyoda, Mama Isale, Yaeda Chini and Maretadu Juu (Map 1) are considered as strong proponents of meeta proscriptions. The main explanation given by informants for this is that these locations are characterized by remoteness, including a lack of interaction with other clans and ethnic groups. Moreover, these four clans are considered to have a tradition of producing powerful medicine men who reinforce the potency of meeta. At present, the most common forms of meeta apply when a girl becomes pregnant outside marriage, or a child dies as a result of a miscarriage, a stillbirth or while still being 
breastfed. We were told by informants that meeta also refers to the death of a husband or wife at a young age. Indeed, we did encounter an informant who stated that he had been subjected to meeta sanctions as a result of the death of his wife during her most fertile years. This case is not discussed here due to insufficient data. This form of meeta also produced the greatest uncertainty and lack of unanimity among informants regarding its relevance, strength and geographical distribution. According to one of our main informants, the head of the Mama Isale clan (Amna Yingi) had proclaimed as long ago as 1974 that widowhood would no longer be considered a reason to exclude either a widow or widower from local community life. Other informants made the point that this form of seclusion had declined, or was no longer practised. For this reason, we do not discuss this form of meeta here.

The two forms of meeta which this paper is concerned with are considered as 'shameful', 'breaking traditional codes of conduct', 'unnatural', 'suspicious' or even 'supernatural' and consequently afflicted individuals have to be excluded from their local communities to protect the community from possible harm. Further, afflicted individuals are only allowed to return to their communities of origin after a period of quarantine that also involves a process of ritual cleansing. This ritual is considered by some women as such a traumatic experience that they are unwilling to undergo this cleansing process and never return to their home communities, but prefer to remain in a space which is beyond traditional control.

11 If a young woman becomes pregnant outside of wedlock, shame is brought on her family and especially the parents as they are considered as having been negligent in their daughter's upbringing. However, most of the blame is directed at the young woman. Usually, birth takes place outside her father's house, to avoid suspicions of the girl's father being the father of the child. At this point, she enters a state of meeta and is physically excluded from her local community. However, her father has the responsibility of finding a family which is willing to accept the girl for the three-year period of meeta. Invariably this will be a non-traditional Iraqw, Christian or Muslim household. Excluding the girl from her own community incurs significant costs for her father, who is obliged to pay the host household with a bull. Of course, the girl's household also loses her labour. If a woman suffers a miscarriage, a stillbirth or the death of a child before it is weaned, this is considered unnatural and the woman is obliged to enter a state of meeta and will be excluded by her family from her village of origin. However, as soon as the woman becomes pregnant again, the seclusion process is revoked since it is proven that the girl is healthy and ritually clean. Until the woman becomes pregnant again, she is obliged to remain in meeta for up to three years. If after this she has still not had any children and wants to return to her clan village, she has to undergo the cleansing ritual as described above.

More generally, the emphasis given to protecting the local community cannot be overstated. As well as the fact that individuals in a state of meeta are obliged to undergo a cleansing process before they are permitted to return to village life, measures to protect the whole village are regularly undertaken. To protect the village from the intrusion of evil spirits, a sheep is sacrificed once a year to placate such evil forces and the intestines are spread around the edge of the village. It is stated that this ritual cleansing also prevents the outbreak of disease. of course, people and domesticated animals do become ill or suffer disease. In cases which are considered of a more serious nature such as dysentery, leprosy, anthrax or injury as a result of an attack by a 
leopard, short-term meeta (meaning exclusion from the community for a period of between seven and ten days) is prescribed by traditional medicine men. Again, the sacrificial slaughter of sheep, goats and chickens to appease disgruntled spirits is undertaken. A range of medicinal herbs are used as treatment. For example, leprosy is considered as a punishment by Looaa for what is considered the extremely serious act of incest, i.e. where a mother has sexual relations with her son or a father with his daughter. Another example concerns the leopard, an animal which is found in Mbulu District but apparently is not commonly encountered, that is often perceived as a danger for the rural population. However, this animal has become the focus of much folklore. Some people are considered to have substantial powers of witchcraft and have the ability to control leopards and use them as a weapon against people. The Manda Do'Bayo clan is a particularly large and powerful group, and certain clan members are said to be able to control the behaviour of leopards. The informant who discussed the idea of the 'controlled leopard' did however add the caveat that 'leopards cannot harm people who are strong Christians'! What is significant about the discussion of leprosy and leopards is that they should best be interpreted as metaphors that reflect a range of powerful proscriptions to protect the traditional Iraqw. As can be seen, much of the discussion surrounding meeta has its own internal cohesion and logic.

There are many women living in exile in Mbulu town as a result of meeta. Some of them have been excluded and exiled from their village due to their state of meeta while others are the children of these excluded women who have not returned to their villages. Below are examples of three women and their experiences with meeta seclusion. While their experiences and strategies adopted vary, they all try to adapt or, at least, cope in a context of urban change.

Cases of urban-based women in MeetaA woman called Maria : Refusal of ritual cleansing

When Maria was 22 and unmarried, she became pregnant in her home village. She was forced to leave the village because of her state of meeta and moved to Mbulu where she rented a room. She was assisted in settling into town by other women who had experienced meeta. The baby was delivered at the District Hospital in Mbulu. Today, Maria is 38 years of age, still unmarried and lives permanently in Mbulu. She has 8 children ranging in age from 2 to 16 who are either at primary school or in kindergarten. Maria survives as an independent woman in an urban setting by doing agricultural labouring for other households, weeding with a hoe, collecting manure for fuel, and gathering firewood. She also brews and sells local alcohol (pombe) and engages in prostitution. Finally, she receives financial assistance from a sister-in-law who lives in the large town of Arusha. Maria could have returned to her parents' home village after a period of eighteen months if she had been willing to undergo a ritual cleansing. She refused as this was against her Catholic beliefs. She is permitted to visit her parents' home but is not allowed to enter the house or sit on a chair, let alone sleep or eat food there. She can talk to her parents but no physical contact is allowed, even shaking hands, for fear of pollution.

The case of Leonia : Survival through the informal economy

Leonia is an unmarried Iraqw mother who is 25 years of age and has been in Mbulu for five years. She runs her own small restaurant (mama nitilie) selling chicken and chips. She was born in the village of Masqaroda (in Tlawi Ward) about $20 \mathrm{~km}$ from Mbulu. She got pregnant when she was 20 and was forced to leave the village because of her state 
of meeta. Like Maria in the previous example, she was also supported by a network of woman who were also in meeta. She gave birth to her son who is now five and goes to kindergarten. The father of her son is a Muslim but whether they have contact was not disclosed. She is a Catholic and would like to get married at some stage. She established her chicken and chip restaurant after having worked in a shop where she was able to save sufficient capital to invest in a stove and other essential accessories. She considers her business to be successful. There are six other women in Mbulu operating similar restaurants and she is not concerned about competition from them, although she would not like to see more restaurants open up. Leonia has exploited a rewarding employment niche in an urban setting, which is very advantageous for her. She does not face competition from the many bars and tea rooms which sell traditional food such as bananas, rice, and maize with sauce.Unless Leonia, like Maria, undergoes a ritual cleansing, her chances of returning to the village are negligible. As an Iraqw woman she is also denied access to agricultural land as this is inherited through males. It would appear that Leonia is best placed facing a future in town with all the opportunities that may arise there.

Mama Fatuma : Transgressing traditional norms of behaviour

Mama Fatuma was born in Mbulu to a Muslim Sambaa father from Tanga and an Iraqw mother. She resides and earns a living in Mbulu town. From the way that she behaves, in sharp contrast to traditional Iraqw values, it is most likely that her mother was a woman in meeta who refused to undergo the cleansing ritual that would have facilitated her return to the 'protection' of the village. Fatuma is probably a woman in her mid-forties. She has never been married and has four children, the youngest is 13 years of age. All her children attend primary and secondary school. Fatuma's main source of income is a bar, located in the internal courtyard of her house, which produces local brew (pombe) using maize as the principle ingredient. She started her pombe business in 1991.

17 Pombe production using maize is a legal activity as long as there are plentiful supplies to meet local food requirements. However, during periods of drought when maize is scarce, the production of pombe from maize is unlawful. Since this is Fatuma's only source of income, she is obliged to produce pombe even when it is not allowed. In an attempt to circumvent the attention of the police during periods of drought, pombe production and sales take place in the porini (the woods). Fatuma employs five women to help her prepare pombe, in addition to three who act as lookouts in case of overzealous police. Occasionally, the police do manage to locate Fatuma's 'bar in the woods'. The punishment for such an offence is a fine of TSh 20,000 or six months in prison. Invariably, Fatuma pays a bribe to the police and continues with her business. Fatuma's pombe business is highly lucrative and on a good day can earn up to TSh 30,000 . To put this in context, the minimum wage for a government worker in Tanzania is between TSh 40,000 and TSh 50,000 per month.

18 It is generally acknowledged in Mbulu that Fatuma produces an excellent pombe, partly because of additives which, it is stated, improve the taste. While she has a good business, the majority of her customers are rural people who spend most during the harvest and post-harvest months from July to October. Otherwise, the busiest days are during the large monthly markets, which are held in Mbulu throughout the year. Many urban people and especially those with the economic wherewithal to visit 'modern' bars (civil servants being a case in point) drink more expensive bottled beer and do not 
frequent more traditional pombe bars. Despite the fact that Fatuma was born and brought up in Mbulu, she is very much an outsider. Her lifestyle stands in sharp contrast to that of traditional Iraqw women. She owns a large house which has electricity, is nicely furnished and has a TV. As a Muslim woman she is not supposed to be involved in the alcohol business in any way. She argues however that her business permits her to care of her children in the best manner possible and that crossing the strict boundaries that should guide her behaviour as a Muslim woman is not a major concern for her. Fatuma has never been married and has no contact with the fathers of her children. She has had many boyfriends and her present one is a wealthy married mill owner from the village of Mama Isale.

Towards an interpretation of Meeta

19 A central issue which this paper attempts to address is how meeta should be interpreted and understood. A fruitful point of departure is to dichotomize the analysis. One interpretation views meeta as a major form of physical and social control through the use of severe punishment (social violence) by elders, invariably elderly men, to demonstrate their power over the community, and particularly over women who are seen as having transgressed the rules and interests of the community. Within such an interpretation, the rituals that women have to go through to be allowed back into the community are considered to be so severe that the majority of women do not return to their home communities but make a new life further afield, for example in the town of Mbulu.The alternative (and opposing) view sees meeta as a cultural praxis where it should not be understood as a punishment but rather as a collection of powerful sanctions to protect the community against what are considered dangerous events or circumstances. If we adopt this view, the seclusion practices of meeta are employed to ensure that the processes of growth, and thus the fertility of humans, animals and the land, are secured.

Exile from the village : The town as a refuge for rural women

It is estimated that 30 per cent of all households in Mbulu town are headed by women. This is similar to the situation elsewhere in Sub-Saharan Africa where many rural women - who are divorced, widowed or single - migrate to towns to find work or to escape the drudgery and confines of rural life (see, for example, Gugler \& Ludwar-Ene $1995: 258-68$ ). While it is true that many of the independent women householders in Mbulu town have left their villages, the reasons behind this migration are due to the sanctions of meeta.

21 For an apparently modernizing society, the tradition of meeta is still very strong. Women who have been in a state of meeta and who get married usually marry non-Iraqw men. However, there are examples also of Iraqw men marrying women in seclusion (Snyder 1993, Selvik 1998). These women can, if they go through the cleansing ritual, return to the confines of the village but the experience of meeta is said to be so traumatic that Iraqw women who have been exposed to the sanction often avoid further contact with traditional Iraqw culture. Very few women return to their villages of origin to live but remain outside meeta space in places like Mbulu and find work as bar girls, run small restaurants, engage in petty trade, or work as prostitutes, just like Maria, Leonia and Mama Fatuma.

22 It is not difficult to produce arguments to support the view that meeta is a form of social violence which can be understood as 'any intentional act that is carried out against another person against their will and that causes psychological suffering or physical 
bodily harm in the course of normal social relations'. This form of exclusion results in a disrupted, even shattered, relationship with the community they once belonged to and a lack of identity and feeling of belonging to the village of origin. Their identity and feeling of belonging are instead grounded in the networks they engage with in town. What the three cases above and many others like them demonstrate is the importance of the urban secular space of Mbulu - a space which provides opportunities for independent women to survive and, in some cases, to accumulate capital. And it is also a space largely devoid of tradition and confinement, which allows for alternative lifestyles and choices. While this can be regarded as a liberating experience by the many women who are forced to leave their villages, the very same urban context can be viewed as a place to be avoided due to the possibility of escape from Iraqw rules and norms of behaviour.

The town as a dangerous space : A new type of 'outside' to the Iraqw 'inside'

Iraqw people conceptualize their world and surroundings according to 'insides' and 'outsides'. Thornton (1980: 83) argues that Mbulu town is 'a sort of a hole in this Iraqw conceptualisation of their land and surroundings'. Selvik (1998:66) argues that Mbulu and other surrounding towns constitute instead a new type of 'outside' to the Iraqw conceptualization of space. This means that Mbulu town is not regulated by the seclusion practices of meeta, and many girls in the state of meeta, especially if pregnant outside of wedlock, are sent to town where they give birth to and raise their children. If the town is seen as a new 'outside' to the Iraqw conceptualization of space, young women in particular have to be careful about moving into this non-meeta space (which corresponds to what we can term 'secular space') because this 'outside' may also imply a way of behaving : being free and beyond the boundaries imposed by traditional meeta space (non-secular space) and clan authority. From the viewpoint of the present discussion, space must be viewed as a relative concept. For example, for many non-Iraqw women as well as women in a state of meeta, the urban space of Mbulu can be seen as a liberating experience but for traditional Iraqw women this urban space should be approached with caution or best be avoided since it can also be a threatening and dangerous space. Entering certain kinds of space may put individuals and communities in danger. Young women have to be careful not to stray into non-traditional Iraqw space for fear of being afflicted by other young Iraqw women who are in a state of meeta. This should be seen in the light of the central position ascribed to women and their life-giving flows (see Rekdal 1996 and Selvik 1998, for further details).

With this interpretation in mind, it would be more difficult to argue that the practices of meeta are to be understood as a form of social violence which should be acted upon or at best eradicated as a tradition that does not belong in a modernized society. On the contrary, meeta should be viewed as a way of protection. Within such an interpretive framework, Maria and Leonia are both women who should have gone through a cleansing ritual to be included into the communities they belong to. As long as they choose not to, they will be avoided by women in a state of procreation for fear of a loss of fertility. Mama Fatuma on the other hand represents, within this perspective, the dangerous space of Mbulu town, understood as the Iraqw 'outside'. It is not an exaggeration to say that traditional Iraqw people do not care much for women like Fatuma. Clearly Mama Fatuma challenges the rules which condition the Iraqw perception of ideal behaviour. She drinks a good deal in the evenings after her bar is 
closed and is often intoxicated. Fatuma is considered as an uncontrollable individual and, as such, is considered a dangerous woman inhabiting dangerous space. This is the kind of space that young Iraqw women must avoid and be protected from

Maria, Leonia and Fatuma can be interpreted as belonging to an Iraqw 'outside' without any relationship with the communities they used to belong to. Consequently, they are regarded as being excluded for life unless they willingly return to their communities after going through the required rituals. Many women like these choose not to, and prefer to find an identity and feeling of belonging in the networks of women in town.

The Iraqw life world contested : Maintaining values through syncretism

On the face of it, Iraqw culture appears to represent a culture being successfully modernized (viz. globalized by the nation state of Tanzania through the widespread use of the Swahili language and other instruments of state power). A good illustration of this is the number of respondents who claim membership of the Catholic Church. Conversion to Catholicism has been an ongoing process for more than a century and represents the success of the Western missionary project.

However having said this, many Catholics simultaneously adhere to the local traditional belief systems. Among many Iraqw, this tendency towards parallel beliefs or syncretism is very strong and effects everyday life in a number of ways. The fact that Looaa is female is related to the strong belief among the Iraqw of the central importance of fertility. It is highly likely that this syncretic model is articulated most strongly through Looaa because she can be compared to the importance of the Virgin Mary and all the Catholic associations surrounding fertility. Many Iraqw maintain traditional Iraqw values through syncretism. According to one central informant named Stephen who is a practising Catholic, there is no conflict inherent in this syncretic approach. For example, if Stephen or a family member became ill and could not find a cure in modern medicine, a traditional Iraqw healer would be consulted. By casting stones and interpreting the way in which they were scattered, a diagnosis would be made and a treatment prescribed. Following this, Stephen would go to confession and ask for forgiveness for believing in a spiritual power other than that of the Church. The simultaneous belief in both Catholicism and local deities is more a matter of a blending or a mix of faiths rather than an issue of either-or. Many Iraqw do live lives which represent both continuity and change within the Iraqw life world. The following example clearly exemplifies this point.

The case of Joseph : One foot in each world

Joseph is 47 years of age and is an Iraqw who claims to be a practising Catholic. He was born in the countryside $25 \mathrm{~km}$ from Mbulu and came to town 'to make money'. He did not reveal how long he has been in town. He owns a small lodging house in the centre of town, and also runs a fairly large one-room tailor's workshop. He employs two young male employees. During periods of fieldwork, we observed that his business appeared to be thriving, although Joseph did express a concern about 'some degree of competition from second-hand clothes traders'. All tailors in Mbulu make school uniforms and cater for both urban and rural demand, an important and lucrative business since all school children have to wear uniform, Apart from this, most customers are from town and include wealthier customers with sufficient money to be able to purchase made-to-measure suits. However, there is significant rural demand for wedding dresses. Joseph travels to Arusha once or twice a month by bus to purchase cloth. A follow-up interview was arranged at Joseph's house on the outskirts of the 
centre of town. The house is built to a very high standard with modern bricks and ceramic roof tiles. It is also connected to the national electricity grid which reached Mbulu in 1999. In the backyard a shed houses a modern hybrid dairy cow - one tangible result of the development activities of a European bilateral donor. Joseph is married to an Iraqw-Indian woman who is in her early thirties, and they have five children ranging in age from two to eight years of age. Joseph's mother-in-law is probably an Iraqw woman who was in meeta as a result of being unmarried and having a child by an Indian. This is supported by the fact that intermarriage between Africans and Asians is extremely rare in Tanzania. During the course of discussions, Joseph disclosed that he also had another, older wife and family in the countryside. Here he has a 1.5 acre shamba (farm) of which one acre is devoted to the growing of coffee. According to Joseph, his country wife has 'mental problems' and is assisted by two grown-up sons aged 21 and 19. The eldest son is married to an Iraqw woman who had had a miscarriage and was subsequently in a state of meeta at the time of the interview.

In this changing world of the Iraqw, Joseph can be viewed as a successful Iraqw man utilizing the opportunities offered by Mbulu town. With his business and his house and assets, Joseph can be seen as a modern urban practising Catholic. Joseph is able to live a married life in town with a woman born out of wedlock without any difficulties. At the same time, he is able to maintain his marriage in his home village. Here he adheres to the belief in the meeta practice of secluding his daughter-in-law due to her miscarriage. It could be argued that Joseph has successfully established a life with one foot in each world, adapting to the changing realities of where he lives.

Concluding remarks

A number of key informants in Mbulu, as well as in the literature on the Iraqw, have pointed to the possibility that meeta sanctions are showing signs of relaxing as a result of a number of factors. Some of the more important include increasing school attendance and the spread of Catholicism, including rapidly growing indigenous Christian movements. Mbulu town is also populated by a large number of outsiders from other parts of Tanzania, which is influencing the Iraqw life world. In addition, the diffusion into Mbulu District of other modernization impulses, such as television, provides the local Iraqw population with alternative world views. Road improvements have also reduced the friction of distance and have helped reduce the former isolation of much of the district. Finally, as access to rural farmland is becoming scarcer (both in terms of the amount and quality), earning a living from the land will become more difficult and precarious. This strongly suggests that some of the rural population (young men without agricultural land and young unmarried women without customary rights to land) will be obliged to permanently leave the land and search for employment opportunities elsewhere. All these changes might lead to a weakening or the eventual dissolution of the strength of clan solidarity and control, thus weakening meeta practices.

31 However, it can also be argued that an understanding of changes taking place in different African communities demands a deconstruction of the modern-traditional dichotomy (Rekdal 1996, Selvik 1998). Consequently, it is necessary to go beyond the assumption that there is a linear, one-way process from traditional to modern life or as Comaroff and Comaroff (1993: xii) say 'the terminus towards which non-western peoples constantly edge'. Rekdal $(1996: 382)$ argues that 'so-called traditional societies .... are not passive victims of external modern forces "having an impact" on them in 
more or less predictable ways .... like all societies Iraqw culture have mechanisms and procedures for coping with change in a manner which ensures cultural continuity'. Selvik (1998) argues likewise that we cannot assume that meeta is simply a remainder of a former tradition, but we should see it as a cultural practice taking on new forms. This is in line with our argument of viewing meeta from different perspectives. The rapid processes of change that have characterized Mbulu town and its surroundings have not eliminated meeta practices, but new meanings of meeta are instead in the process of being created.

It could perfectly well be argued that the seclusion practices of meeta are a form of social violence where the victims of the practice are secluded and where the relationship with the community is cut off and the women are left in a state of limbo or of not belonging. However, doing this we have to bear in mind that when we apply a western perspective we are turning a cultural practice into a phenomenon of social violence where the term social violence actually has a meaning. If we, on the other hand, in our interpretation also include the rich context of the Iraqw life world, it is possible to argue the opposite and that the seclusion practices of meeta should be understood as a form of protection rather than punishment.

\section{BIBLIOGRAPHIE}

Baker, J. 2001, 'Migration as a Positive Response to Opportunity and Context : The Case of Welo, Ethiopia', in : M, de Bruijn, R. van Dijk \& D. Foeken (eds), Mobile Africa : Changing Patterns of Movement in Africa and Beyond, Leiden, Brill, p. 107-125.

Baker, J. \& H. Wallevik 2003, 'Poverty and Wealth at the Rural-Urban Interface : An Actor-Centred Perspective from Northern Tanzania', Environment \& Urbanization 15 (2), p. 229-48.

Comaroff, J. \& J. Comaroff 1993, 'Introduction', in : J. Comaroff \& J. Comaroff (eds), Modernity and its Malcontents. Ritual and Power in Post-colonial Africa, Chicago, University of Chicago Press.

Gugler, J. \& G. Ludwar-Ene 1995, 'Gender and Migration in Africa South of the Sahara', in J. Baker \& Tade Akin Aina (eds), The Migration Experience in Africa, Uppsala, Nordic Africa Institute.

Meindertsma, J.D. \& J.J. Kessler 1997, 'Towards Better Use of Environmental Resources. A

Planning Document of Mbulu and Karatu Districts, Tanzania', The Hague, Netherlands Ministry of Foreign Affairs.

Mous, M. 1992, A Grammar of Iraqw, Leiden, University of Leiden.

Rekdal, O.B. 1996, 'Money, Milk and Sorghum Beer : Change and Continuity among the Iraqw of Northern Tanzania', Africa 66 (3), p. 367-85.

Rekdal, O.B. \& A. Blysrad 1999, 'We are as Sheep and Goats : Iraqw and Datooga Discourses on Fortune, Failure and the Future', in : D.M Anderson \& V. Broch-Due (eds), The Poor are Not Us : Poverty and Pastoralism in Eastern Africa, Oxford : James Currey, Nairobi, E.A.E.P, Athens, Ohio University Press. 
Selvik, E. 1998, 'Channeling Flows of Blood and Water. A Study of Gender, Fertility and Seclusion Practices among Iraqw People in Tanzania', Cand. Polit. Thesis. Oslo, University of Oslo.

Snyder, K. 1993, 'Honey and Water : Moral Ideology and the Construction of Community among the Iraqw of Northern Tanzania', PhD Thesis, Yale University.

Thornton, R.J. 1980, Space, Time and Culture among the Iraqw of Tanzania, New York, Academic Press.

Thornton, R.J. 1982, 'Modelling of Spatial Relations in a Boundary-marking Ritual of the Iraqw of Tanzania', Man 17 (3), 528-45.

URT (United Republic of Tanzania), 2003, '2002 Population and Housing Census, General Report', Dar es Salaam.

Winter, E.H. 1968, 'Some Aspects of Political Organization and Land Tenure among the Iraqw', Kyoto University African Studies 2, pp. 1-29.

\section{NOTES}

1. The authors would like to acknowledge the financial support provided for this study by the Research Council of Norway.

2. Much of the detail referring to the socio-economic structure of Mbulu and the three surrounding villages is drawn from Baker \& Wallevik (2003).

\section{RÉSUMÉS}

Dans cette communication, nous aborderons principalement le groupe ethnique Iraqw localisé dans le Nord de la Tanzanie. La discussion sera axée sur une pratique culturelle dénommée meeta qui fait référence à une série de pratiques d'isolation employées par les Iraqw. Cette communication mettra en évidence la façon dont meeta peut être comprise dans une perspective occidentale et perçue comme un acte de violence sociale. D'un autre côté, la communication présentera également une interprétation de meeta dans une perspective Iraqw où ces pratiques d'isolation sont davantage perçues comme des règles protégeant les communautés Iraqw contre des influences nocives. Cette communication traitera ainsi des opinions divergentes à l'égard de cette pratique culturelle et de la façon dont les Iraqw vivent ces divergences. Les données ont été rassemblées à Mbulu, une ville imporatnte quoique de petite taille ainsi que dans trois localités rurales attenantes dans le district de Mbulu situé dans la région nouvellement établie de Manyara.

Title: Changing life worlds and contested space: Seclusion practices among the Iraqw of Northern Tanzania. The focus of this paper is a discussion of the Iraqw ethnic group in northern Tanzania. The discussion concerns the cultural practice of meeta, which refers to a set of seclusion practices employed by the Iraqw. In this paper we discuss different understandings of these cultural practices. It reveals how meeta can be understood from a western perspective, and thus understood as social violence. On the other hand, the paper presents an interpretation of 
meet $a$ as seen from an Iraqw perspective where these seclusion practices are seen more as a set of regulations protecting Iraqw communities from harmful influences. Thus, the paper deals with the contested meanings of this cultural practice and how the Iraqw people live with these contested meanings. Data were collected from the small, but important, town of Mbulu and three surrounding rural locations in Mbulu District in the newly-created Manyara Region. 